\title{
Fourth to Sixth Grade Teachers' Invented Real World Problems and Pictorial Representations for Fraction Division
}

\author{
Micah Stohlmann ${ }^{1 *}$, Yichen Yang ${ }^{1}$, Xing Huang ${ }^{2}$, Travis Olson ${ }^{1}$ \\ ${ }^{1}$ University of Nevada, Las Vegas, USA \\ ${ }^{2}$ University of Florida, Florida, USA \\ *CORRESPONDENCE: $\square$ micah.stohlmann@unlv.edu
}

\begin{abstract}
Teaching fraction operations for conceptual understanding is a challenging task. For the topic of fraction division especially, teachers need support because teachers find this difficult to teach and elementary and middle school students struggle to learn this concept. Well-structured professional development can assist teachers in exploring their own understanding as well as how to incorporate multiple representations in their instruction. This naturalistic inquiry study investigated fourth to sixth grade teachers' invented real-world problems and pictorial representations for fraction division. The teachers completed a written assessment focused on conceptual understanding of fraction operations through multiple representations at the beginning and conclusion of a weeklong professional development experience. The questions on the assessment were taken or modified from prior research studies. The results in this paper focus specifically on a task in which the teachers had to develop a real world story problem for $2 \frac{1}{2} \div$ $\frac{3}{4}$ and solve the problem by drawing a pictorial representation. The teachers showed statistically significant improvement on developing appropriate real-world problems and using pictorial representations to solve their problems. Implications for teachers' usage of multiple representations are discussed along with needed structures for professional development targeted on fractions.

Keywords: elementary, fraction division, middle school, professional development, representations
\end{abstract}

\section{INTRODUCTION}

Since Shulman's (1986) seminal work, the importance of mathematical knowledge for teaching has been discussed often and investigated. One of the topics that has been researched in connection to teachers' knowledge is fractions. Fractions have received focus because a developed understanding of fractions, as part of rational number reasoning, is needed for success in learning algebra (National Mathematics Advisory Panel, 2008; Siegler et al, 2012). Also, it is a topic area that many teachers find challenging to learn and to teach (Lamon, 2007; Lo \& Luo, 2010; Tirosh, 2000). Elementary teachers often need support for their mathematical knowledge of fractions and are less confident in this area (Ball, Lubienski, \& Mewborn, 2001). In particular, research on teachers' understanding of fraction division has highlighted deficiencies and a lack of conceptual understanding (Ball, 1990; Borko et al., 1992; Li \& Kulm, 2008; Ma, 1999; Nillas, 2003). Too often fraction division is taught procedurally with a focus on memorization of steps and fraction division has long been considered the least conceptually understood topic in elementary school (e.g. Payne, 1976).

\section{Article History: Received 7 February $2019 \bullet$ Revised 8 August $2019 \bullet$ Accepted 17 August 2019}

(C) 2020 by the authors; licensee Modestum Ltd., UK. Open Access terms of the Creative Commons Attribution 4.0 International License (http://creativecommons.org/licenses/by/4.0/) apply. The license permits unrestricted use, distribution, and reproduction in any medium, on the condition that users give exact credit to the original author(s) and the source, provide a link to the Creative Commons license, and indicate if they made any changes. 
The need to support teachers' improvement in knowledge and skills needed for teaching conceptually is well-recognized in many educational systems (e.g. Li \& Kulm, 2008). One view of conceptual understanding is connected knowledge that can be demonstrated through multiple representations (Lesh, 1979). Understanding concepts through multiple representations has a long history in mathematics education (e.g. Bruner, 1966; Kaput 1987) as well as with understanding fractional concepts (e.g. Behr, Wachsmuth, Post, \& Lesh, 1984). Studies done on teachers' understanding of fraction division have highlighted the importance of the realistic and pictorial representations in supporting conceptual understanding (Chen \& Li, 2010; Leung \& Carbone, 2013). At the same time it has been noted that teachers make limited use of pictorial representations in their teaching of fraction division (Jacobson \& Izsák, 2015; Lo \& Luo, 2012) and have difficulty in developing correct real world story problems for fraction division (Ball, 1990, Lo \& Luo, 2012; Nillas, 2003). In light of this, further research has been called for in regards to professional development experiences aimed at improving teachers' conceptual understanding of fraction division in regards to realistic and pictorial representations (Jacobson \& Izsák, 2015; Leung \& Carbone, 2013).

With the above research in mind, we sought to develop in-service teachers conceptual content knowledge of fraction division through the ability to create appropriate real world problems and pictorial representations used to solve the problems. Fourth to sixth grade teachers participated in a weeklong professional development experience focused on fractional number sense and fraction operations through multiple representations. The research question that guided this study is as follows: What is the impact of a professional development experience focused on multiple representations on $4^{\text {th }}$ to $6^{\text {th }}$ grade teachers' ability to create real world problems and pictorial representations for fraction division?

\section{TEACHERS’ UNDERSTANDING OF FRACTION DIVISION}

Research by Greer (1992) and Simon (1993) has identified two types of division meanings: measurement division and partitive division. In measurement division, one tries to determine how many groups of the intended quantity are contained in the given quantity (object or collection of objects). For example, with " $24 \div$ $1 / 2$ " using the measurement model, students could be asked, "Hamdi works as a chef and has 24 pounds of fish. If a serving size is $1 / 2$ a pound; how many servings can she make?" For this question the number of groups is unknown. The $1 / 2$ represents the amount in each group.

In partitive division, the given quantity (an object or collection of objects) is equally divided into a given number of groups, and the goal is to determine the amount or size in each group. For example, with $24 \div 1 / 2$, using the partitive model, students could be asked, "Hamdi works as a chef and is cooking for a large group. She has 24 pounds of fish, which is half of the total amount that she needs. How many pounds of fish does Hamdi need?" In this question the total amount of fish is unknown or in general how much in each group. The divisor " $1 / 2$ ", represents the current number of groups.

Some research has suggested approaching division of fractions from a partitive perspective because of its intuitive nature (Empson, 1995; Van de Walle, 2007). Its potential is often limited to having whole numbers as the divisor though. This has led to the suggestion of the introduction of fraction division through a measurement context. In our study we took this approach and while partitive division was discussed, the majority of the time on connecting representations was spent on a measurement interpretation.

Ma's (1999) comparative study of Chinese and U.S. elementary teachers brought attention to the topic of fraction division. In Ma's study, fewer than half of the U.S. teachers were able to give a correct solution to a fraction division problem, while the Chinese teachers showed greater coherence and flexibility in their knowledge and explanations. The Chinese teachers demonstrated a knowledge package that included the meaning of division with whole numbers, concept of inverse operation, meaning of multiplication with fractions, meaning of multiplication with whole numbers, meaning of addition, concept of unit, and concept of fraction. This knowledge package was also demonstrated in another study with eighteen in-service Chinese elementary teachers ( $\mathrm{Li} \&$ Huang, 2008). It should be noted that the use of elementary teachers that only teach mathematics is more common in China than in the United States.

In a study with forty-five Taiwanese preservice elementary teachers at the beginning of their mathematics methods course it was determined that forty of the teachers had developed the knowledge package of fraction division as proposed by Ma. This knowledge package may need to be added to as fourteen out of the forty preservice elementary teachers were unable to develop a correct realistic problem for $8 \frac{2}{3} \div \frac{1}{4}$ or develop an appropriate pictorial representation to illustrate a solution process (Lo \& Luo, 2012). Elementary students in 
Taiwan are not required by the national curriculum to pose realistic problems or use pictorial diagrams to demonstrate understanding with fraction division (Lo \& Luo, 2012). In addition, while pictorial representations are presented in Chinese textbooks, there are no requirements for students to explain how fraction division works pictorially and this has been suggested as an area that could be improved (Li, 2008).

Studies done with U.S. teachers have found difficulties with teachers' conceptual understanding of fraction division. In a study with nineteen preservice teachers Ball (1990) found that the teachers could not write a story problem for $1 \frac{3}{4} \div \frac{1}{2}$. Nillas (2003) found a similar result with four elementary preservice teachers when asked to write a story problem for $\frac{5}{7} \div \frac{1}{2}$. Both studies found that students' invented story problems incorrectly involved division by two. In another study with forty-six U.S. preservice middle school teachers it was found that the teachers had limited mathematics knowledge needed for teaching fraction division conceptually. The preservice middle school teachers were completing a mathematics methods course at the time of the study but fraction division was not focused on during the course (Li \& Kulm, 2008). In the three studies above no intervention specific to fraction division was tested in order to improve the teachers' understanding.

A study that involved seventy-two Hong Kong preservice elementary teachers had the teachers write a realistic problem for $2 \frac{1}{2} \div \frac{1}{2}$. Analysis of the problems posed showed that many of the preservice teachers had incorrectly interpreted the division concept in their problems as sharing so their problems aligned with dividing by two. A short intervention was then done that involved discussing the changing role of the referent whole for fraction addition and multiplication. The teachers then showed significant improvement in posing correct realistic problems with the measurement context. On the pre and post-test all teachers who attempted to pose a problem with a partitive context did so incorrectly. It is stated that additional studies should be conducted to show the effects of different teaching interventions for improving conceptual understanding of fraction division (Leung \& Carbone, 2013). Our study extends this work by including a division sentence that does not have a whole number answer as well as requiring teachers to solve their invented problems with a pictorial representation. It has been suggested that one of the major reasons students struggle with fractions is that it requires attending to the referent unit (Philipp \& Hawthorne, 2015). In order for teachers to develop this understanding in students it is important that they are able to make sense of the unit with fraction division (Cramer, Monson, Whitney, Leavitt, \& Wyberg, 2010). Our research also advances prior work by examining the effects of an intervention specifically focused on fraction division through multiple representations with U.S. teachers.

\section{CONCEPTUAL KNOWLEDGE THROUGH MULTIPLE REPRESENTATIONS}

A widely agreed upon view of mathematical content knowledge is that it consists of conceptual and procedural knowledge. Hiebert and Lefevre (1986) define conceptual knowledge as a "connected web of knowledge, a network in which the linking relationships are as prominent as the discrete pieces of information" (p.3). Conceptual knowledge involves having knowledge that is connected. To further elaborate on this The Lesh Translation Model (Lesh, 1979, see Figure 1) can be used. It was originally designed to represent understanding of conceptual mathematical knowledge. It consists of five categories of representation: (1) Representation through realistic, real-world, or experienced contexts, (2) Symbolic representation, (3) Language representation, (4) Pictorial representation, and (5) Representation with manipulatives (concrete, hands-on models). 


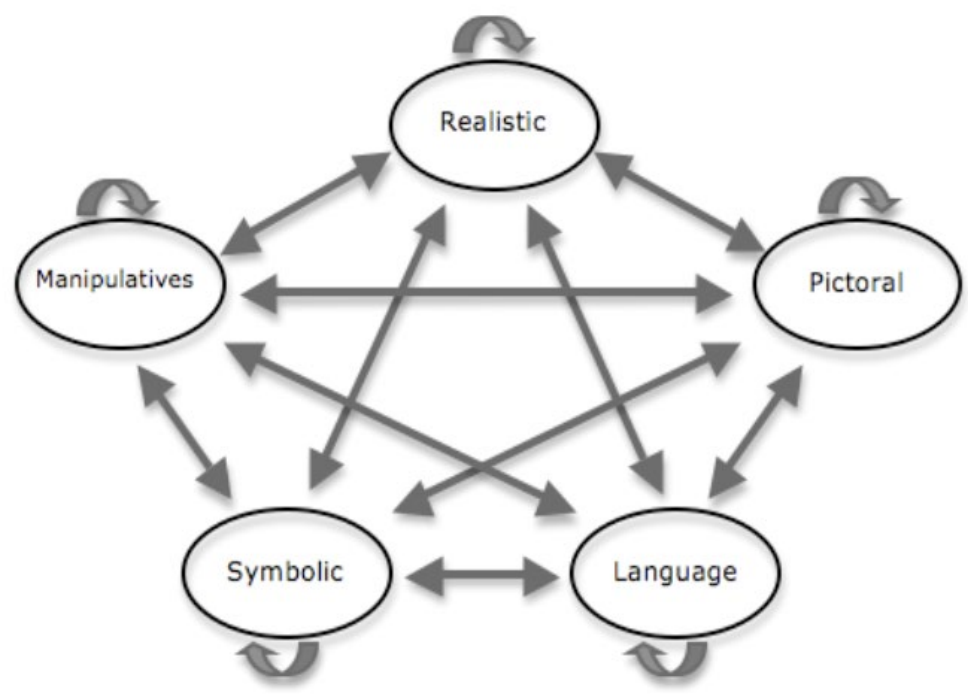

Figure 1. The Lesh Translation Model

The National Council of Teachers of Mathematics (NCTM, 2014) describe using and connecting mathematical representations as an effective teaching practice that makes it more likely for a diverse group of students to learn mathematics conceptually. When students learn to make connections between multiple representations they demonstrate deeper mathematical understanding and enhanced problem-solving abilities (Fuson, Kalchman, \& Bransford, 2005). Young learners especially benefit from these experiences (National Research Council, 2009) and pictorial representations are of particular importance for English language learners, learners with special needs, or struggling learners. This is because the pictorial representations allow more students to participate meaningfully in the mathematical discourse in the classroom (Fuson \& Murata, 2007). Teachers need to have knowledge through multiple representations to help students make sense of fractions in this way. A few key points that teachers should be able to do are described by NCTM (2014) including (a) introducing forms of representations that can be useful to students, (b) asking students to make math drawings or use other visual supports to explain and justify their reasoning, and (c) design ways to elicit and assess students' abilities to use representations meaningfully to solve problems.

In regards to realistic representations, several researchers suggest that the ability to pose problems, or to write problems for students to complete that are applicable to their lives, is an important measure of teachers' competence in terms of conceptual understanding (e.g. Carbone, 2009; Leung \& Carbone, 2013; Mack, 1995; Shin, 2010). Also, as noted earlier, pictorial representations are important for developing conceptual understanding of fraction division (Chen \& Li, 2010).

In summary, prior research has demonstrated the need for improvement in elementary teachers' conceptual understanding for fraction division (Ball, 1990; Li \& Kulm, 2008; Ma, 1999; Nillas, 2003). In this prior research no intervention specific to fraction division was tested in order to improve the teachers' understanding. Our study is similar to the study of Leung \& Carbone (2013) and extends this work by including a division sentence that does not have a whole number answer as well as requiring teachers to solve their invented problems with a pictorial representation. In our study teachers needed to have a greater understanding of the referent unit to correctly use their pictorial representation to come to the correct solution. One of the major reasons students struggle with fractions is that it requires attending to the referent unit (Philipp \& Hawthorne, 2015). It is important that teachers are able to make sense of the unit with fraction division to develop this understanding with their students (Cramer, Monson, Whitney, Leavitt, \& Wyberg, 2010).

Research has been called for in regards to professional development experiences aimed at improving teachers' conceptual understanding of fraction division in regards to realistic and pictorial representations (Jacobson \& Izsák, 2015; Leung \& Carbone, 2013). Our research serves to give an example of a well-designed professional development experience for teachers that can develop their understanding of fraction division through multiple representations. This in turn should lead to greater opportunities for students to have 


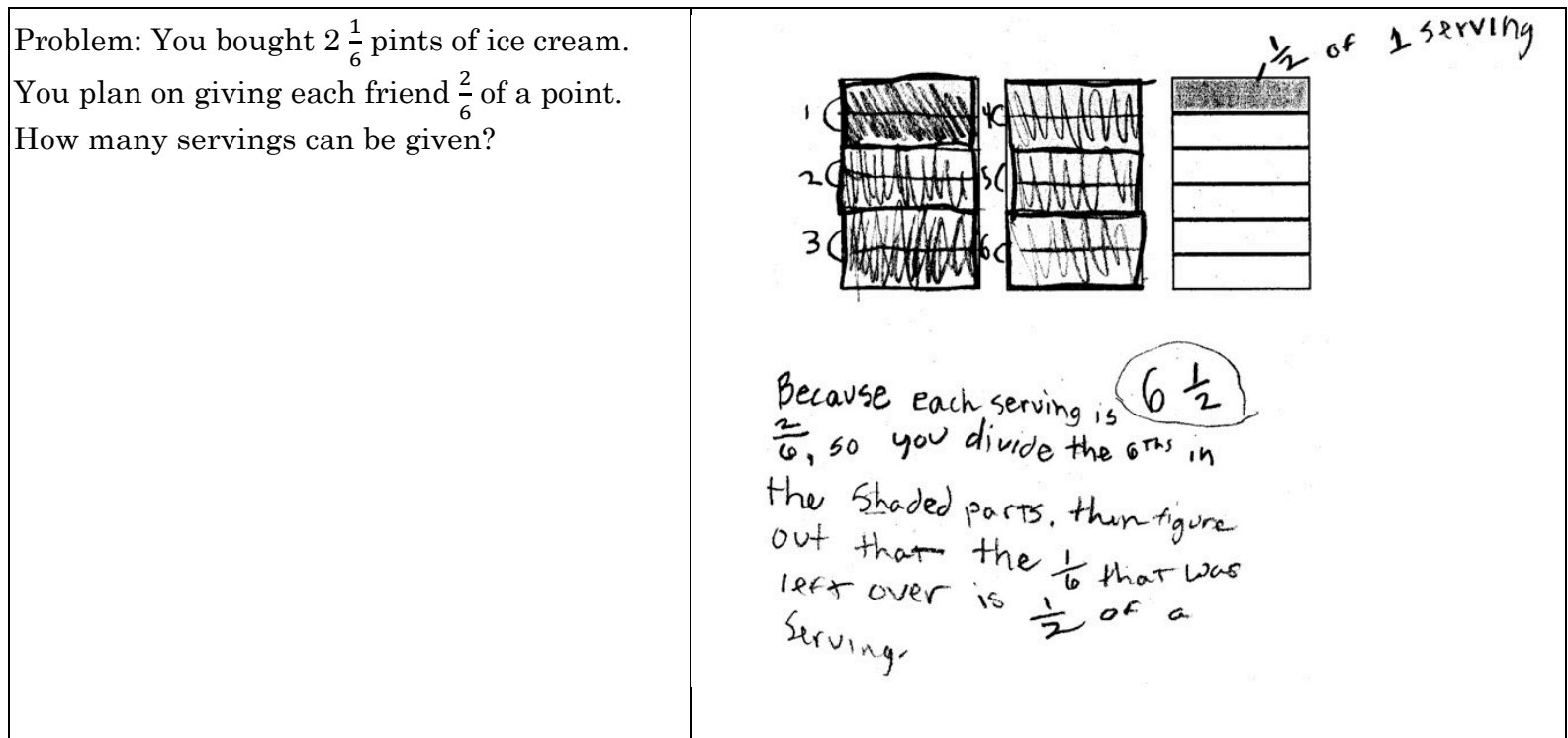

Figure 2. Example story problem and student work teachers discussed

experiences with multiple representations of fractions that can lead to both procedural and conceptual understanding.

\section{METHODS}

This is a naturalistic inquiry study (Patton, 2002) in which we used a deductive coding strategy using a list of preset codes (Corbin \& Strauss, 2008). The study was conducted with 77 fourth to sixth grade teachers in a large urban school district in the Southwestern portion of the United States. The professional development program the teachers participated in focused on developing the teachers' subject matter knowledge and pedagogical content knowledge in regards to fraction operations.

The professional development in this study was designed with the characteristics of high quality professional development that include (a) a minimum of 20 hours of contact time; (b) extended duration; (c) participation by teachers from the same grade, school or subject; (d) active learning opportunities; (e) coherence with other school, district, state or national reform efforts; and (f) a focus on subject matter content (Desimone, Porter, Garet, Yoon, \& Birman, 2002; Garet, Porter, Desimone, Birman, \& Yoon, 2001). The professional development in this study lasted 21 hours over five days in the summer.

The professional development activities related to fraction division entailed one and a half days of the five day professional development. First the teachers were shown a video of a child being instructed through rote steps and memorization for how to solve a fraction division problem. Discussion occurred about the instruction the child received and if in three days the child would be able to solve similar problems. Another video was then shown of the same child, three days later being unable to remember the procedure that was shown to her for fraction division (Integrating Mathematics and Pedagogy, 2004). The teachers then learned about and discussed research from the Rational Number Project. The activities focus on teachers' own strategies for solving fraction division problems, the difference in measurement and partitive interpretations of division, using pictorial and realistic representations with a measurement interpretation, common denominator division, estimation, and examining student work. Figure 2 gives one example of student work the teachers discussed after developing their own pictorial representations to help them solve the problem.

The teachers were then given two problem sets (Figure 3) and worked on drawing pictorial representations for the realistic problems and then selecting the number sentence(s) that correspond to each problem. The teachers then met with another group and shared their ideas. A large group discussion occurred after this. 


\section{Problem set A}
a. $6 \div 2$
b. $6 \div \frac{1}{2}$
c. $6 \times 2$
d. $6 \times \frac{1}{2}$

1. Maura has 6 cups of flour. Each batch of cookies requires $\frac{1}{2}$ cup of flour. How many batches of cookies can she make?

2. Maura has 6 batches of cookies. She plans to share them equally with her friend, Jamilla. How many batches will each of them get?

3. Maura has to travel 6 miles. When she walks, she covers $\frac{1}{2}$ mile in an hour. How many hours will it take her?

4. Maura has to travel 6 miles. She plans to walk halfway and run halfway. How far will she run?

\section{Problem set B}
a. $\frac{5}{6} \div 2$
b. $\frac{5}{6} \div \frac{1}{2}$
c. $\frac{5}{6} \times 2$
d. $\frac{5}{6} \times \frac{1}{2}$

5. Maura has $\frac{5}{6}$ cup of flour. Each batch of cookies requires $\frac{1}{2}$ cup of flour. How many batches of cookies can she make?

6. Maura has $\frac{5}{6}$ of a batch of cookies. She plans to share them equally with her friend, Jamilla. How many batches will each of them get?

7. Maura has to travel $\frac{5}{6}$ mile. When she walks, she covers $\frac{1}{2}$ mile in an hour. How many hours will it take her?

8. Maura has to travel $\frac{5}{6}$ mile. She plans to walk halfway and run halfway. How far will she run?

Figure 3. Multiplication and division context activity

$$
\frac{4}{5} \div \frac{2}{3}=\frac{\frac{4}{5}}{\frac{2}{3}}=\frac{\frac{4}{5} \times \frac{3}{2}}{\frac{2}{3} \times \frac{3}{2}}=\frac{4}{5} \times \frac{3}{2} .
$$

Figure 4. One way to explain why fraction division is equivalent to multiplying by the reciprocal

One of the teacher leaders of the professional development then facilitated a discussion, drawing on the teachers' ideas, for why it is equivalent to multiply by the reciprocal when doing fraction division. This was done by writing a fraction division problem like a complex fraction and then solving as shown in Figure 4. There was a discussion of each step focused on a rationale for why it works.

The teachers then worked on a problem that had several questions (Figure 5). The teachers worked individually and then discussed as a whole group their responses. The instructor emphasized the importance of being able to connect the symbolic and pictorial representations. Connecting to the rationale in Figure 4 the teachers had to explain where each quantity could be seen in their pictorial representation. In the case of Wanda's cake task this included: $4, \frac{3}{5}, 6 \frac{2}{3}$, and $\frac{5}{3}$. The final activity related to fraction division the teachers completed was to develop their own realistic story problems with fractions for all four operations. 


\title{
Wanda really likes cake. She decides that one serving should be $\frac{3}{5}$ of a cake. She has 4 cakes, all the same size. How many servings does she have?
}

\author{
a. Draw a diagram to model this situation. \\ b. What answer does your diagram indicate? \\ c. Solve the problem using an arithmetic sentence. \\ d. How does your arithmetic sentence match your diagram? \\ e. After 6 servings are eaten, how much cake is left?
}

f. For the division problem $4 \div \frac{3}{5}$, why is the answer $6 \frac{2}{3}$ rather than $6 \frac{2}{5}$ ?

Figure 5. Wanda's cake task

Table 1. Coding scheme

\begin{tabular}{lll}
\hline Story problem codes & Pictorial representation codes & Correctly solved based on the picture \\
\hline -no story problem given & -no picture given & -Yes \\
-correct story problem- & -correct number line model & -No \\
measurement & -incorrect number line model & -No- $1 / 4$ interpreted as the amount left over \\
-correct story problem- & -correct area model & -No answer provided \\
partitive & -incorrect area model & -only correct symbolic work shown \\
-incorrect story problem- & & -only incorrect symbolic work or no work shown \\
\hline
\end{tabular}

Table 2. General contingency table for McNemar's test

\begin{tabular}{lccc}
\hline & Test 2 positive & Test 2 negative & Row total \\
\hline Test 1 positive & $\mathrm{a}$ & $\mathrm{b}$ & $\mathrm{a}+\mathrm{b}$ \\
\hline Test 1 negative & $\mathrm{c}$ & $\mathrm{d}$ & $\mathrm{c}+\mathrm{d}$ \\
\hline Column total & $\mathrm{a}+\mathrm{c}$ & $\mathrm{b}+\mathrm{d}$ & $\mathrm{n}$ (total number of participants) \\
\hline
\end{tabular}

\section{Data Collection and Analysis}

The teachers took a pre-assessment at the beginning of the professional development and a post assessment at the end. The results in this study focus specifically on the following question:

Write a story problem for the fraction division problem. Then draw a picture to solve.

$$
2 \frac{1}{2} \div \frac{3}{4}
$$

The data analysis was conducted by a deductive coding strategy using a list of preset codes (Corbin \& Strauss, 2008). The first author drew on knowledge of working with the teachers during the professional development to develop a coding scheme based on the three main parts of the question (Table 1). Two doctoral students then used the coding scheme to individually code the pre and post responses to the questions. The doctoral students then met to discuss their work. The Cohen's K coefficient of inter-rater agreement was .86, and thus within an acceptable range (Fleiss, 1981; Landis \& Koch, 1977). Once coding differences were identified, the raters came to agreement on the discrepancies so that full agreement was reached. In the results more detail will be provided for each code and the teacher reasoning for correct representational work.

The McNemar's test (Pett, 1997) was used to determine if there was a statistically significant improvement in the correct-incorrect ratio of story problems, pictorial representations, and correct solutions based on the picture from the pre-assessment to the post-assessment. The test is used on paired nominal data and is applied to $2 \times 2$ contingency tables to determine whether the row and column marginal frequencies are equal (Table 2). The null hypothesis states that the two marginal probabilities of each outcome are the same. $p_{a}+p_{b}=p_{a}+$ $p_{c}$ and $p_{c}+p_{d}=p_{b}+p_{d}$ 
Table 3. Story problem results

\begin{tabular}{ccccc}
\hline $\begin{array}{c}\text { Story problem } \\
\text { code }\end{array}$ & $\begin{array}{c}\text { No story problem } \\
\text { given }\end{array}$ & $\begin{array}{c}\text { Correct story problem- } \\
\text { measurement }\end{array}$ & $\begin{array}{c}\text { Correct story } \\
\text { problem- partitive }\end{array}$ & $\begin{array}{c}\text { Incorrect story } \\
\text { problem }\end{array}$ \\
\hline Pre & $32(41.6 \%)$ & $31(40.3 \%)$ & $1(1.3 \%)$ & $13(16.9 \%)$ \\
\hline Post & $6(9.5 \%)$ & $45(71.4 \%)$ & $0(0 \%)$ & $12(19 \%)$ \\
\hline
\end{tabular}

Table 4. Incorrect story problem examples and descriptions

\begin{tabular}{|c|c|c|c|}
\hline Categorization & $\begin{array}{l}\text { Number of } \\
\text { teachers on the } \\
\text { pre-assessment }\end{array}$ & $\begin{array}{l}\text { Number of } \\
\text { teachers on the } \\
\text { post-assessment }\end{array}$ & Example and description \\
\hline Context issues & 1 & 0 & $\begin{array}{l}\text { There are } 21 / 2 \text { chocolate bars. Each student should get } 3 / 4 \text { of a } \\
\text { bar. How many students will get } 3 / 4 \text { of a bar? } \\
\text { For this problem it is not possible to have a fractional } \\
\text { amount of a student, so if a student answered this correctly } \\
\text { with } 3 \text { they would not solve the given division sentence. }\end{array}$ \\
\hline No question & 2 & 1 & $\begin{array}{l}\text { Lewis had } 21 / 2 \text { apples. He had } 3 \text { friends and shared } 3 / 4 \text { to } \\
\text { each friend. } \\
\text { No question is provided. }\end{array}$ \\
\hline Not written clearly & 6 & 7 & $\begin{array}{l}\text { Seeme had } 21 / 2 \text { candy bars. She wants to break them into } \\
\text { pieces of equal lengths. How many pieces can she get? } \\
\text { In this problem it is not stated that the equal lengths be } 3 / 4 \\
\text { of a candy bar, which would fit the division sentence. }\end{array}$ \\
\hline $\begin{array}{l}\text { Multiplication instead } \\
\text { of a division problem }\end{array}$ & 4 & 4 & $\begin{array}{l}\text { George walked } 21 / 2 \text { miles / day. George was able to run } 3 / 4 \text { of } \\
\text { his walk. How much did George run? } \\
\text { This story problem aligns with multiplication. }\end{array}$ \\
\hline
\end{tabular}

\section{RESULTS}

The teachers showed significant improvement from the pre-assessment to the post-assessment. The results will be discussed focusing on the story problem results first, then the pictorial representations, and finally whether the problem was correctly solved based on the picture. There were 77 teachers that completed the pre-assessment and 63 teachers that completed the post-assessment. A McNemar's test (Pett, 1997) determined that there was a statistically significant improvement in the correct-incorrect ratio of story problems of 25:38 on the pre-assessment and 45:18 on the post-assessment, $\left(\chi^{2}=20, p<.001\right)$. This was based just on the 63 teachers who completed both the pre and post-assessment. Table 3 has the pre and post results for the story problem codes. Due to rounding, the row percentage totals may not equal 100\%.

On the post-assessment the vast majority of the teachers provided a story problem as opposed to the preassessment. The correct story problems included different contexts. The teachers wrote problems involving food, cooking, distance, construction, and clothing. The majority of the story problems focused on food. A few correct example story problems from the post-assessment are provide below.

- Mary has $2^{1 / 2}$ cups of rice in the cooker. She needs $3 / 4$ cup to make a sushi roll. How many sushi rolls can she make?

- The trip from Adi's house to Kate's house is 2 1/2 miles. She takes $3 / 4$ mile each hour. How long does it take her to walk to Kate's house?

- Each burger at In-N-out requires $3 / 4$ pound of beef. The cook only has $21 / 2$ pounds of meat left. How many burgers can he make?

For the first and third story problem the distinction is not made that there be a complete sushi roll or burger. This enables an answer to still be 3 and 1/3. Since the professional development did not focus on the partitive interpretation of division it is not surprising that the numbers in this column are low.

The incorrect story problems had context issues, did not include a question, were not written clearly, or were written for multiplication instead of a division sentence. On the pre-assessment for these four categories the number of teachers were 1, 2, 6, and 4 respectively. On the post-assessment for these four categories the number of teachers were $0,1,7$, and 4 respectively. Table 4 provides examples for each categorization along with a description for why the story problem is incorrect. 
Table 5. Pictorial representations results

\begin{tabular}{cccccc}
\hline $\begin{array}{c}\text { Pictorial } \\
\text { representation code }\end{array}$ & $\begin{array}{c}\text { No picture } \\
\text { given }\end{array}$ & $\begin{array}{c}\text { Correct number } \\
\text { line model }\end{array}$ & $\begin{array}{c}\text { Incorrect number } \\
\text { line model }\end{array}$ & $\begin{array}{c}\text { Correct area } \\
\text { model }\end{array}$ & $\begin{array}{c}\text { Incorrect area } \\
\text { model }\end{array}$ \\
\hline Pre & $39(50.6 \%)$ & $9(11.7 \%)$ & $0(0 \%)$ & $20(26 \%)$ & $9(11.7 \%)$ \\
\hline Post & $19(30.2 \%)$ & $11(17.5 \%)$ & $0(0 \%)$ & $27(42.9 \%)$ & $6(9.5 \%)$ \\
\hline
\end{tabular}

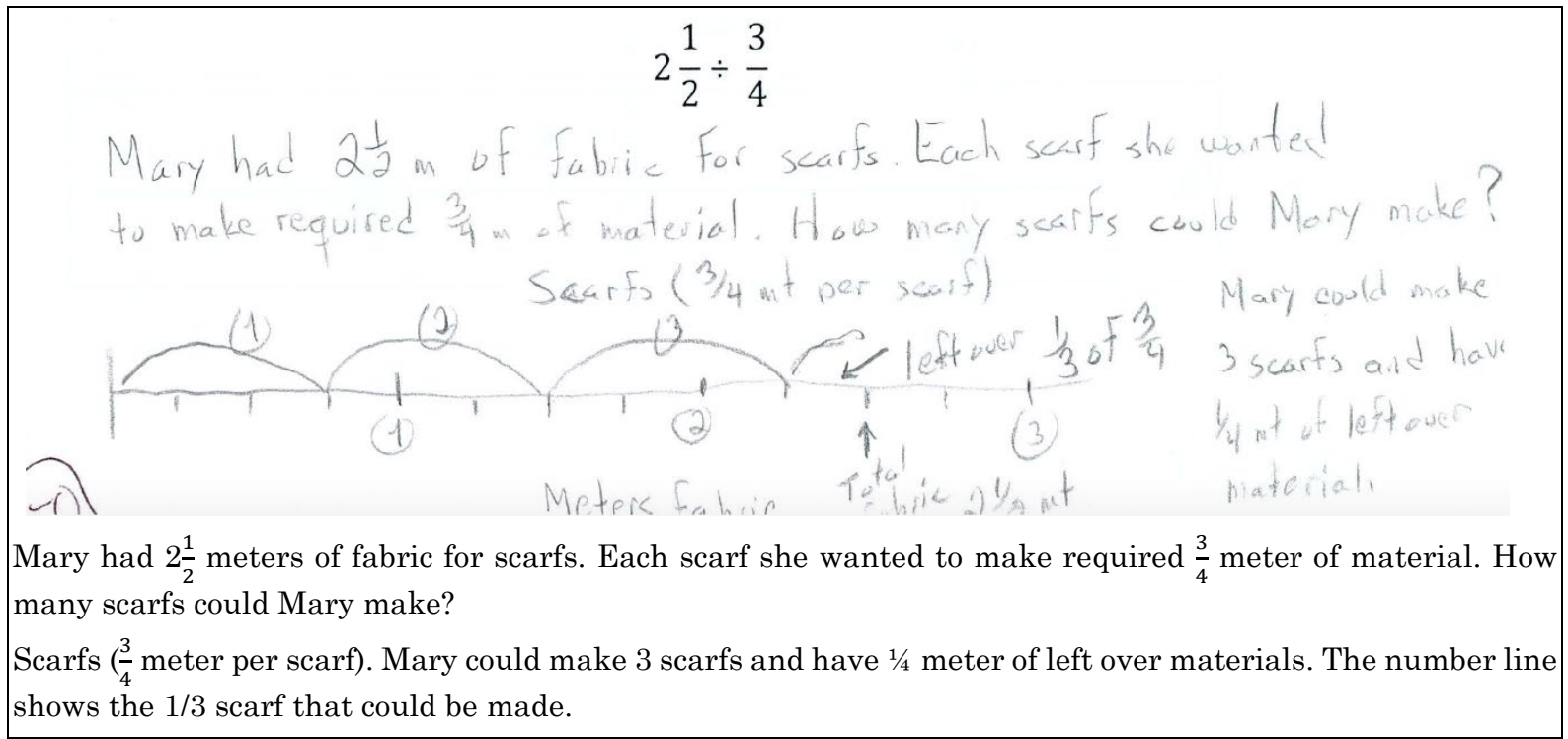

Figure 6. Correct number line model from post-assessment

\section{Pictorial Representations}

The teachers made significant improvements on their ability to develop a correct pictorial representation. A McNemar's test (Pett, 1997) determined that there was a statistically significant improvement in the correct-incorrect ratio of pictorial representations of 22:41 on the pre-assessment and 38:25 on the postassessment, $\left(\chi^{2}=16, p<.001\right)$. Table 5 displays the pictorial representation results. For both the pre and post assessment all of the teachers that used the number line model used it correctly. For those teachers that provided a pictorial representation the majority used an area model. Similar to the pre-assessment results for the story problems, a large percentage of teachers did not provide a picture.

The number line models that were used involved partitioning the number line into fourths up to $2 \frac{1}{2}$ or going beyond $2 \frac{1}{2}$ but marking $2 \frac{1}{2}$ as the stopping point. The teachers then circled or highlighted groups of $3 / 4$ and then noted in some way the left-over amount that could not make a full group. Figure 6 has an example correct number line model. In this example the teacher also noted the correct answer of 3 and $1 / 3$ and that the amount left over in the context of the problem could be considered $1 / 4$ meter as well. The teacher's written work is rewritten under the number line to ensure the problem and explanation can be read clearly.

The majority of the correct area models used were rectangles, but some circles were used as well. The teachers showed 3 or $2 \frac{1}{2}$ rectangles and then marked or circled groups of $3 / 4$, having partitioned the area model into fourths. Figure 7 displays an example correct area model. 


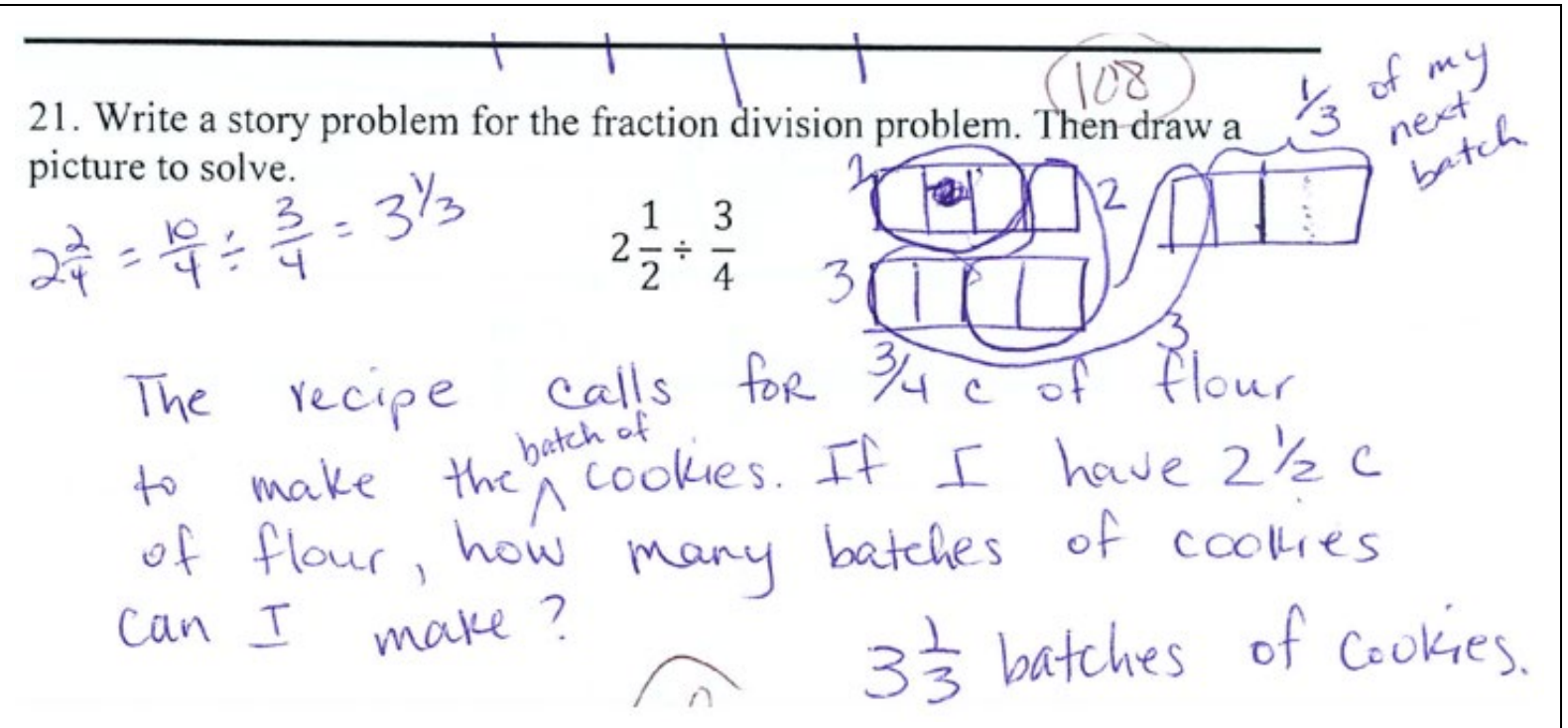

Figure 7. Correct area model from post-assessment

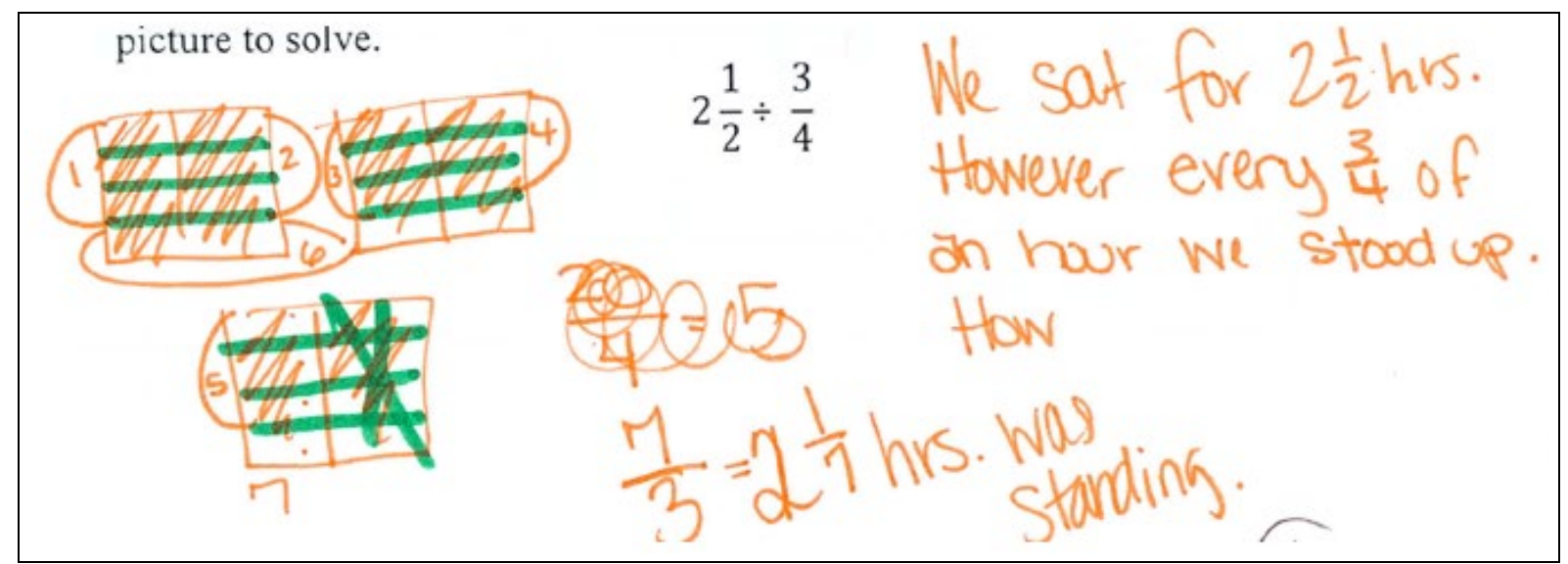

Figure 8. Incorrect area model from post-assessment

The incorrect area models were the result of trying to fit a picture to an incorrect story problem or not properly partitioning the area model or iterating the groups of three-fourths. Figure 8 has an example incorrect area model. Though the teacher showed $2 \frac{1}{2}$ with the area model, the model was partitioned into eighths instead of fourths. The teacher then proceeded to circle groups of three-eighths. The incorrect story problem might have made it harder as well to try to get an accurate picture.

\section{Correctly Solved}

The teachers significantly improved on their ability to correctly solve the fraction division problem based on their provided picture. A McNemar's test (Pett, 1997) determined that there was a statistically significant improvement in the correct-incorrect ratio of being able to solve based on the picture of 16:47 on the preassessment and 28:35 on the post-assessment, $\left(\chi^{2}=12, p<.001\right)$. If a teacher did not provide a picture, then they were coded one of the last two codes focusing only on the symbolic work (Table 6). On the pre-assessment a little more than half of the teachers $(n=39)$ did not provide a pictorial representation. The vast majority $(n=34)$ also did not correctly solve the problem using symbolic work. On the post-assessment 11 of the teachers had a pictorial representation but incorrectly stated that the amount leftover was $1 / 4$ and not $1 / 3$ of a group of $3 / 4$ for a correct answer. The number of teachers who only used symbolic work and were incorrect decreased greatly. 
Table 6. Correctly solved results

\begin{tabular}{ccccccc}
\hline $\begin{array}{c}\text { Solved based } \\
\text { on the }\end{array}$ & Yes & No & $\begin{array}{c}\text { No-1/4 interpreted } \\
\text { as the amount left } \\
\text { picture codes }\end{array}$ & $\begin{array}{c}\text { No answer } \\
\text { provided }\end{array}$ & $\begin{array}{c}\text { Only correct } \\
\text { symbolic work }\end{array}$ & $\begin{array}{c}\text { Only incorrect } \\
\text { symbolic work } \\
\text { or no work }\end{array}$ \\
\hline Pre & $23(29.9 \%)$ & $9(11.7 \%)$ & $5(6.5 \%)$ & $1(1.3 \%)$ & $5(6.5 \%)$ & $34(44.2 \%)$ \\
\hline Post & $28(44.4 \%)$ & $5(7.9 \%)$ & $11(17.5 \%)$ & $1(1.6 \%)$ & $7(11.1 \%)$ & $11(17.5 \%)$ \\
\hline
\end{tabular}

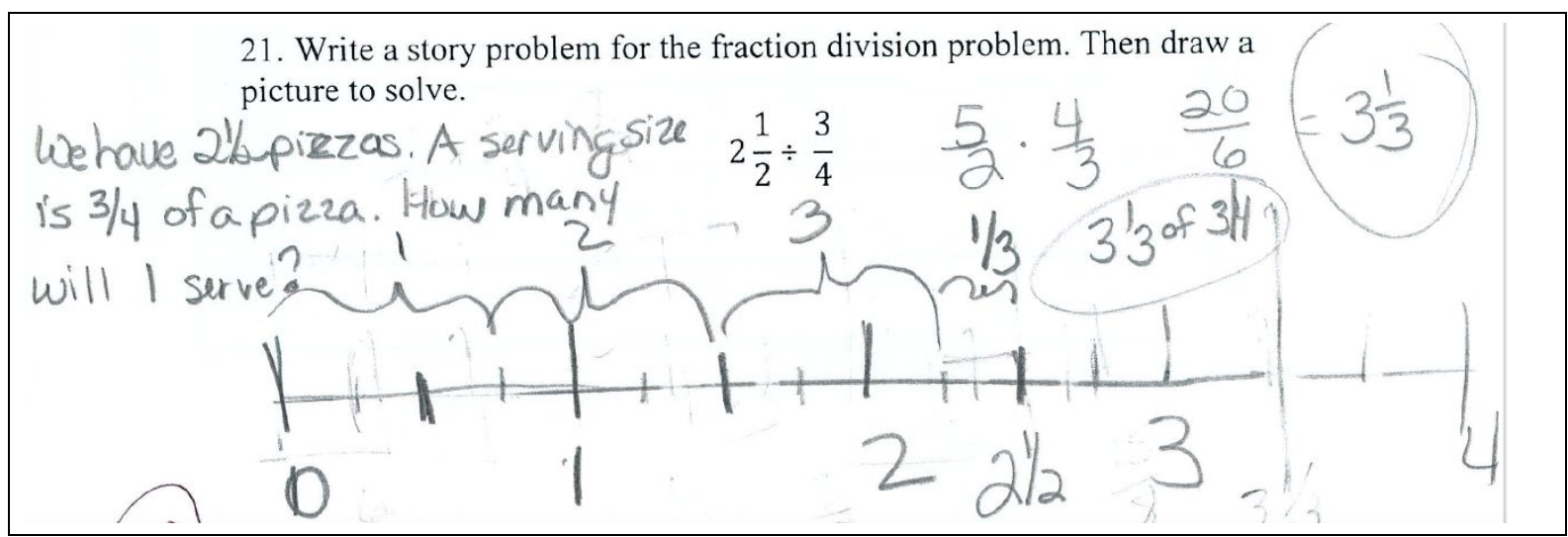

Figure 9. Correctly solved based on the picture from post-assessment

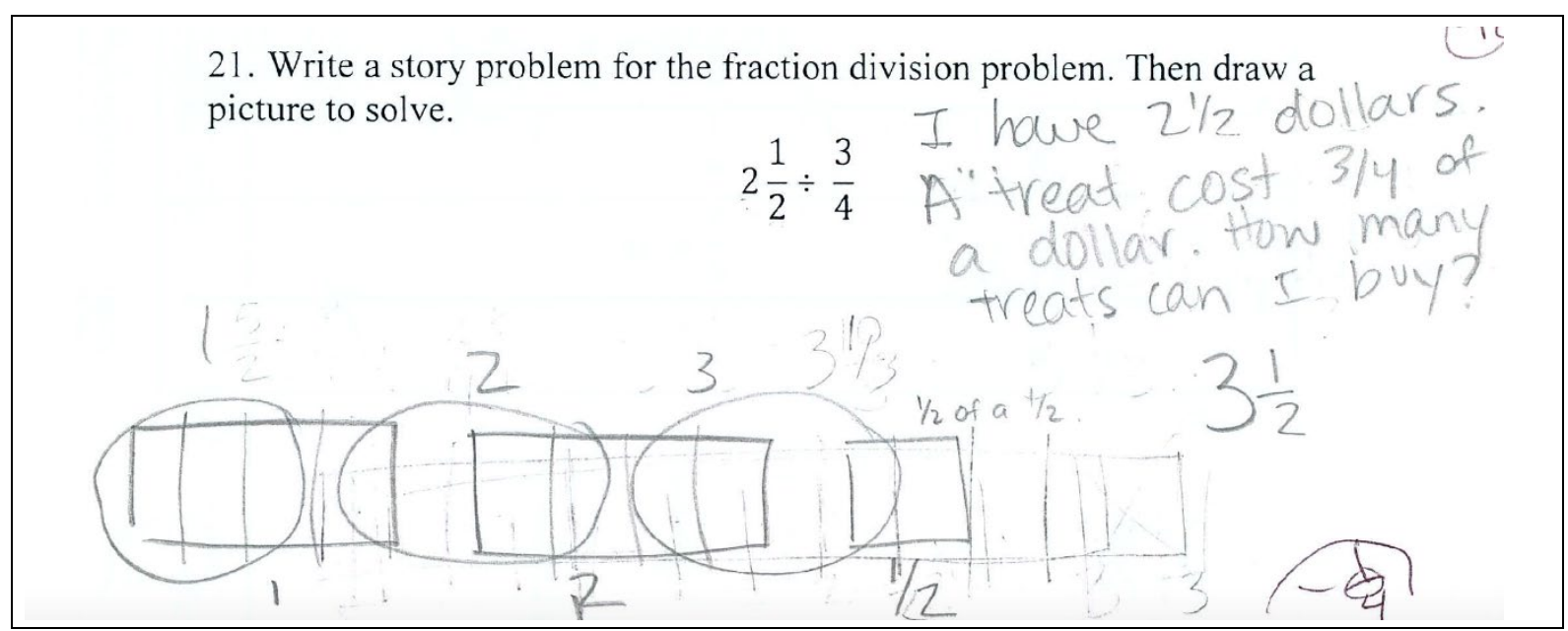

Figure 10. Not correctly solved based on the picture from post-assessment

The teachers that correctly used their picture to solve the problem were able to iterate groups of $3 / 4$ and also then note that the $1 / 4$ that was left over was $1 / 3$ of a group of $3 / 4$. Figure 9 has an example of a teacher that correctly solved the problem based on the picture. The answer of 3 and 1/3 is clearly labeled based on the work done with the pictorial representation. The story problem this teacher provided could have been a little clearer by asking, "how many servings do I have?" As written it could be interpreted as the number of people being served which would be a whole number answer.

There were 9 teachers on the pre-assessment and 5 on the post-assessment that provided a picture but did not get an answer of 3 and $1 / 3$ or 3 and $1 / 4$. Figure 10 has an example where the teacher interpreted the amount leftover as $1 / 2$ because it was $1 / 2$ of the last rectangle. However, the teacher could have realized that the last rectangle was a $1 / 2$ meaning that the piece leftover was $1 / 4$ or a $1 / 3$ of the next group.

There were 5 teachers on the pre-assessment and 11 teachers on the post-assessment that ended up with an answer of $3 \frac{1}{1 / 4}$. In the professional development when these types of problems were done with the teachers it was noted that there are two different ways of interpreting the amount left over that would not make a complete group. It was also stated that one of these interpretations leads to the correct symbolic work. In the context of the problem depending on what was being asked $1 / 4$ could be considered correct. For example, for the story problem in Figure 11 if the question asked for the cups of rice leftover, then it would be $1 / 4$ cup of rice 


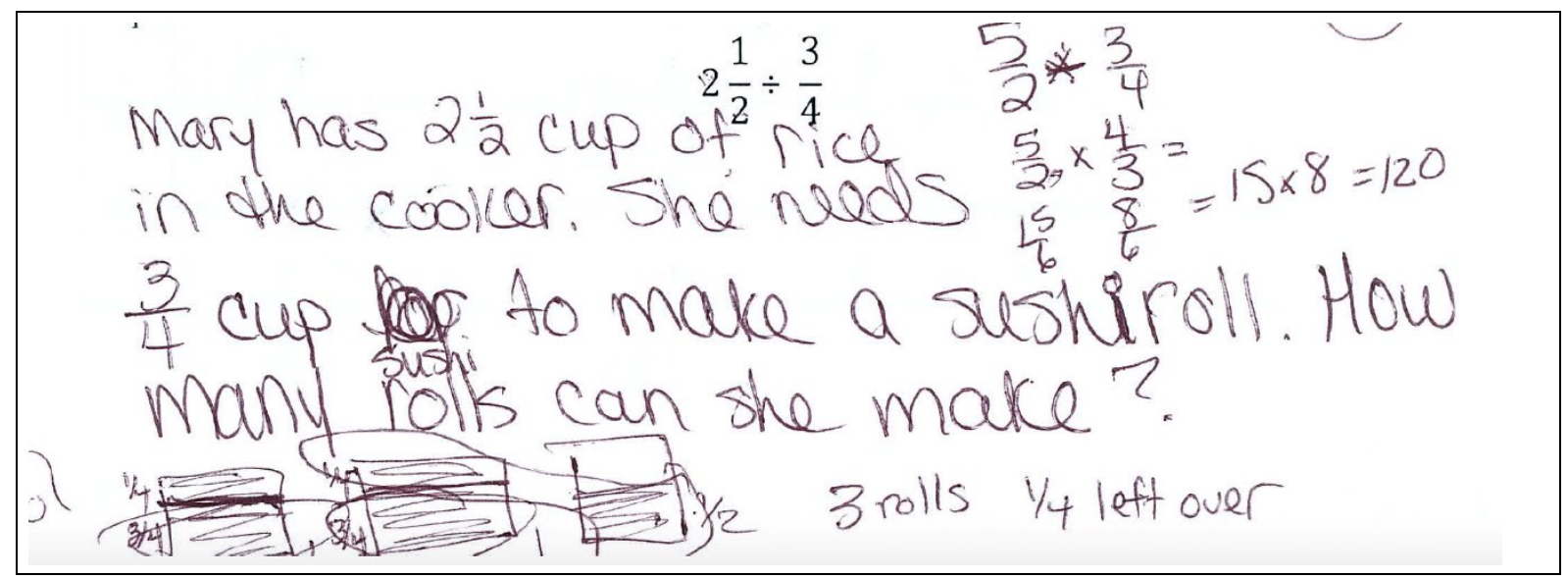

Figure 11. 1/4 interpreted as the amount left over from post-assessment

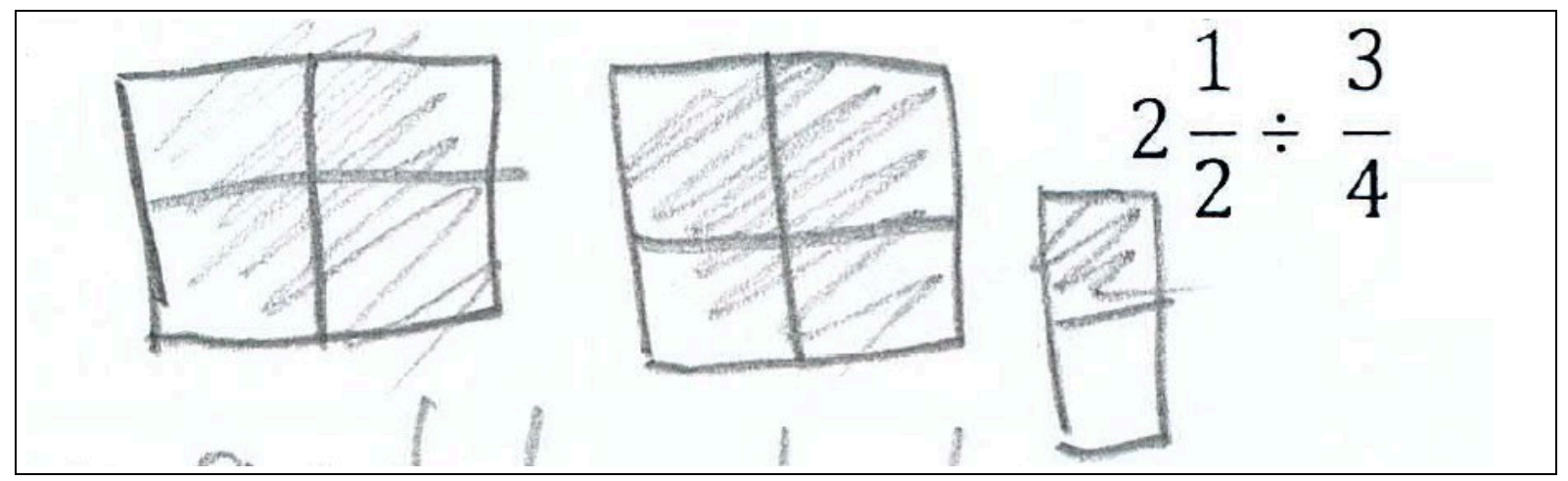

Figure 12. No answer provided from post-assessment

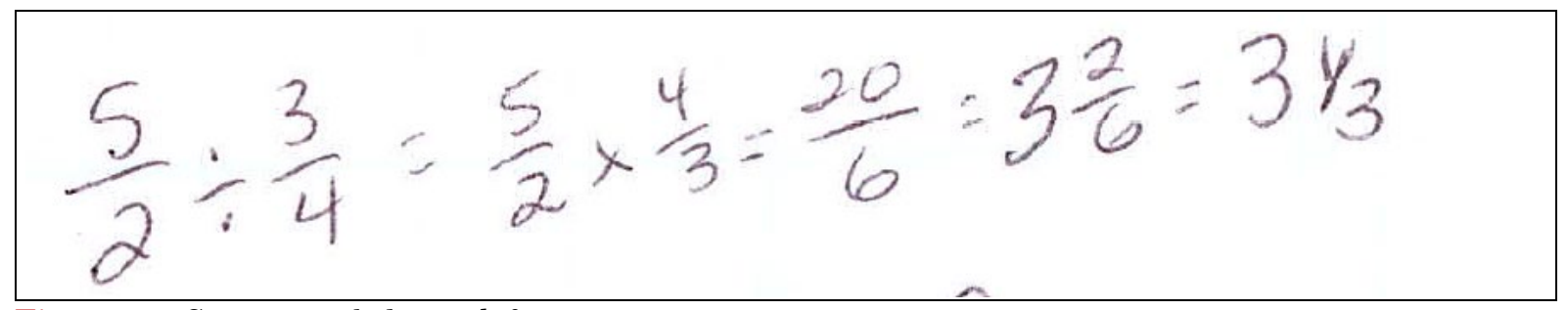

Figure 13. Correct symbolic work from post-assessment

left over. Since the number sentence was given to the teachers in this problem, it was expected that they would provide an answer of $31 / 3$. Since more teachers on the post-test provided $3 \frac{1}{4}$ as the answer, this might not have been as clear to the teachers.

There was only one teacher on the pre and post assessment that did not provide an answer who also provided a pictorial representation. In Figure 12 it is shown how the teacher showed $2 \frac{1}{2}$ but did not know what to do to correctly find the answer.

The number of teachers who only provided correct symbolic work without a picture was low on the preassessment and post-assessment with 5 and 7 respectively. These teachers still relied on the invert and multiply procedure (Figure 13). The example teacher had a correct story problem but did not provide a picture.

Almost half of the teachers $(n=34)$ on the pre-assessment and 11 on the post-assessment did not provide a picture and had incorrect symbolic work. Of the 34 teachers on the pre-assessment, before any professional development, 19 of the teachers left the entire problem blank. An additional 12 teachers made mistakes in trying to use the invert and multiple procedure. The teachers had parts of the procedure that they tried to remember but could not execute it accurately. Figure $\mathbf{1 4}$ has one example of a teacher that incorrectly attempted the invert and multiply procedure. On the post-assessment of the 11 teachers, only one teacher left 


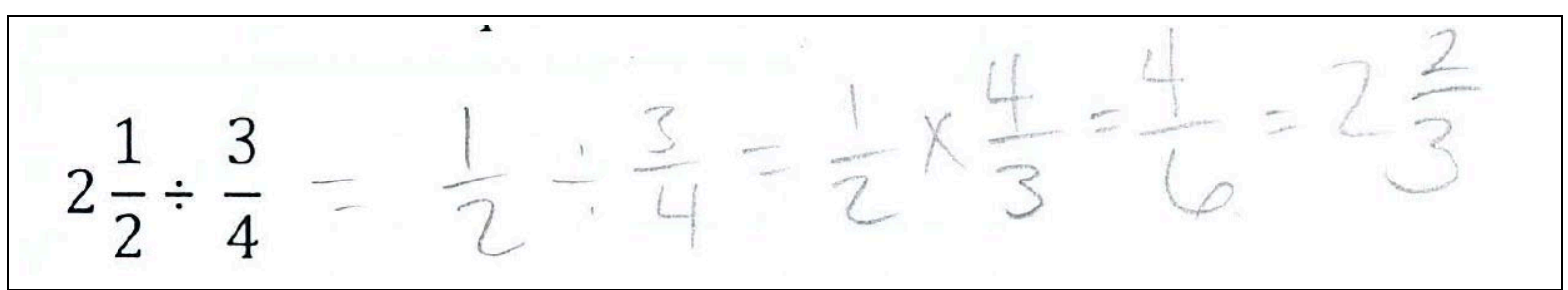

Figure 14. Incorrect symbolic work from post-assessment

the entire problem blank, five had story problems but no symbolic work and five of the teachers incorrectly tried to use the invert and multiply procedure.

\section{DISCUSSION AND CONCLUSION}

Mathematical knowledge for teaching is a multi-faceted and complex construct that teachers should continually strive to improve. Research on teachers' understanding of fraction division has highlighted deficiencies in conceptual understanding including creating realistic problems and developing pictorial representations to solve problems (Ball, 1990; Leung \& Carbone, 2013; Lo \& Lou, 2012; Nillas, 2003). Both realistic and pictorial representations are an important part of conceptual understanding (Leung \& Carbone, 2013). This study was conducted to investigate the impact of a professional development focused on multiple representations on $4^{\text {th }}$ to $6^{\text {th }}$ grade teachers' ability to create real world problems and pictorial representations for fraction division. The results showed that the in-service teachers made significant improvements in their ability to create realistic problems and develop pictorial representations to be used to solve the problems.

This study adds to the research base by demonstrating an effective sequence of experiences to assist teachers to develop conceptual understanding for fraction division. The professional development included the opportunity for teachers to make explicit connections with translations between representations including analyzing student work. Teachers also were able to share their current ways of thinking about fraction division and be provided with experiences to advance this knowledge. Through discussing videos of procedural instruction based on memorization the teachers were able to see the benefits of conceptual understanding through multiple representations. The need for professional development focused on conceptual understanding was seen at the beginning of our study. On the pre-assessment only $30 \%$ of the teachers were able to correctly solve the fraction division problem based on the picture they provided.

Ma (1999) details a useful knowledge package for fraction division, though the pictorial representation does not receive explicit focus in this knowledge package. This has been noted as a possible area of improvement (Li, 2008; Lo \& Luo). When mathematical experiences involve pictorial and realistic representations, it is more likely for a diverse group of students to be successful. This study demonstrated that with the right experiences, teachers are able to develop this pictorial understanding that can aid their understanding of the other representations. In the U.S. the benefits of this approach have been demonstrated. When the Lesh Translation Model has been used as a theoretical foundation for fraction mathematics instruction, students have demonstrated more conceptually based thinking (Cramer, Post \& delMas, 2002).

Prior research on teachers' understanding of fraction division connected to creating story problems and pictorial representations involved problems where the divisor was a unit fraction (Ball, 1990; Ma, 1999; Nillas, 2003; Leung \& Carbone, 2013; Lo \& Luo, 2012). When this occurred it was found that teachers sometimes incorrectly created story problems for a whole number divisor. For example, when the divisor is $1 / 2$ they created a story problem that would fit a divisor of two. This was not seen in our study given that the divisor was $3 / 4$. The most common ways that the teachers developed incorrect story problems were in writing a story problem involving multiplication and not providing enough information for the problem to interpreted clearly. On the post-assessment over $70 \%$ of the teachers were able to write correct story problems though.

Eleven out of sixty-three teachers on the post-assessment had difficulty in working with the concept of a referent unit in using their pictorial representations to solve their problems. This was seen when they interpreted the amount leftover in their representation as $1 / 4$ instead of as $1 / 3$ of a group of $3 / 4$. It has been suggested that one of the major reasons students struggle with fractions is that it requires attending to the referent unit (Philipp \& Hawthorne, 2015). It is important that teachers have a developed understanding of referent unit so that they can help students make the unit or whole explicit. The teachers showed growth in 
their conceptual understanding of fraction division but the referent unit was an area where further improvement could be made.

Students need conceptual understanding of fractions as this topic is used throughout middle school, high school, and college level mathematics. For this to occur it is imperative that teachers have robust knowledge through different representations. The different experiences in this professional development enabled the teachers to see the need for giving students experiences with different representations for the topic of fractions. The teachers improved significantly in their conceptual knowledge of fraction division. It is interesting to note that all of the teachers that used a number line model did so correctly. It has been suggested that the number line model be sequenced after students have had experiences with other models that enable them to build strong mental images of fractions as numbers (Cramer, Ahrendt, Monson, Wyberg, \& Miller, 2017). Future research could investigate if the ability to represent fractional understanding on the number line is related to conceptual understanding of fractions in general. Future research could also investigate the impact of this or a similar professional development that then follows teachers into the classroom to focus on any change in teaching practice and the impact on student learning.

\section{Disclosure statement}

No potential conflict of interest was reported by the authors.

\section{Notes on contributors}

Micah Stohlmann - University of Nevada, Las Vegas, USA.

Yichen Yang - University of Nevada, Las Vegas, USA.

Xing Huang - University of Florida, Florida, USA.

Travis Olson - University of Nevada, Las Vegas, USA.

\section{REFERENCES}

Ball, D. (1990). Prospective elementary and secondary teachers' understanding of division. Journal for Research in Mathematics Education, 21(2), 132-144. https://doi.org/10.2307/749140

Ball, D., Lubienski, S., \& Mewborn, D. (2001). Research on teaching mathematics: The unsolved problem of teachers' mathematical knowledge. In V. Richardson (Ed.), Handbook of research on teaching (4th ed.). (pp. 433-456). New York: Macmillan.

Behr, M., Wachsmuth, I., Post, T. R., \& Lesh, R. (1984). Order and equivalence of rational numbers: A clinical teaching experiment. Journal for Research in Mathematics Education, 15(5), 323-341. https://doi.org/10.2307/748423

Borko, H., Eisenhart, M., Brown, C., Underhill, R., Jones, D., \& Agard, P. C. (1992). Learning to teach hard mathematics: Do novices and their instructors give up too easily? Journal for Research in Mathematics Education, 23(3), 194-222. https://doi.org/10.2307/749118

Bruner, J. (1966). On cognitive growth. In J. S. Bruner, R. R. Oliver, \& P. M. Greenfield (Eds.), Studies in cognitive growth: A collaboration at the Center for Cognitive Studies (pp. 1-67). New York: John Wiley and Sons, Inc. https://doi.org/10.1080/00207596608247117

Carbone, R. (2009). Elementary teacher candidates' understanding of rational numbers: An international perspective. In L. Paditz \& A. Rogerson (Eds.), Proceedings of the mathematics in $21^{\text {st }}$ century project $11^{\text {th }}$ international conference. (pp. 101-105). Dresden, Germany.

Chen, X., \& Li, Y. (2010). Instructional coherence in chinese mathematics classroom-A case study of lessons on fraction division. International Journal of Science and Mathematics Education, 8(4), 711-735. https://doi.org/10.1007/s10763-009-9182-y

Corbin, J., \& Strauss, A. (2008). Basics of qualitative research (3 ${ }^{\text {rd }}$ ed.). Thousand Oaks, CA: Sage. https://doi.org/10.1177/1094428108324688

Cramer, K., Ahrendt, S., Monson, D., Wyberg, T., \& Miller, C. (2017). Making sense of third-grade students' misunderstandings of the number line. Investigations in Mathematics Learning, 9(1), 19-37. https://doi.org/10.1080/19477503.2016.1245035 
Cramer, K., Monson, D., Whitney, S., Leavitt, S., \& Wyberg, T. (2010). Dividing fractions and problem solving: Reflect and discuss. Mathematics Teaching in the Middle School, 15(6), 338-346.

Cramer, K., Post, T., \& delMas, R. (2002). Initial fraction learning by fourth-and fifth-grade students: A comparison of the effects of using commercial curricula with the effects of using the rational number project curriculum. Journal for Research in Mathematics Education, 33(2), 111-144. https://doi.org/10.2307/749646

Desimone, L., Porter, A., Garet, M., Yoon, K., \& Birman, B. (2002). Effects of professional development on teachers' instruction: Results from a three-year longitudinal study. Educational Evaluation and Policy Analysis, 24(2), 81-112. https://doi.org/10.3102/01623737024002081

Empson, S. B. (1995). Using sharing situations to help children learn fractions. Teaching Children Mathematics, 2(2), 110-114.

Fleiss, J. (1981). Statistical methods for rates and proportions. New York: John Wiley.

Fuson, K., \& Murata, A. (2007). Integrating NRC principles and the NCTM process standards to form a class learning path model that individualizes within whole-class activities. National Council of Supervisors of Mathematics Journal of Mathematics Education Leadership, 10(1), 72-91.

Fuson, K., Kalchman, M., \& Bransford, J. (2005). Mathematical understanding: An introduction. In M. Donovan \& J. Bransford (Eds.), How students learn: History, mathematics, and science in the classroom. (pp. 217-256). Washington, D.C.: National Academies Press.

Garet, M.S., Porter, A.C., Desimone, L., Birman, B.F., \& Yoon, K.S. (2001). What makes professional development effective? Results from a national sample of teachers. American Educational Research Journal, 38(4), 915-945. https://doi.org/10.3102/00028312038004915

Greer, B. (1992). Multiplication and division as models of situations. In D. A. Grouws (Ed.), Handbook of research on mathematics teaching and learning (pp. 276-295). New York: Macmillan

Hiebert, J., \& Lefevre, P. (1986). Conceptual and procedural knowledge in mathematics: An introductory analysis. In J. Hiebert (Ed.), Conceptual and procedural knowledge: The case of mathematics (pp. 128). Hillsdale, NJ: Lawrence Erlbaum Associates, Inc.

Integrating Mathematics and Pedagogy (2004). IMAP Web-Based Beliefs-Survey manual. San Diego, CA: Center for Research in Mathematics and Science Education, San Diego State University. Retrieved from http://www.sci.sdsu.edu/CRMSE/IMAP/pubs.html

Jacobson, E., \& Izsák, A. (2015). Knowledge and motivation as mediators in mathematics teaching practice: the case of drawn models for fraction arithmetic. Journal of Mathematics Teacher Education, 18(5), 467-488. https://doi.org/10.1007/s10857-015-9320-0

Kaput, J. (1987). Representation systems and mathematics. In C. Janvier (Ed.), Problems of representation in the teaching and learning of mathematics (pp. 19-26). Hillsdale, NJ: Erlbaum.

Lamon, S. (2007). Rational numbers and proportional reasoning: Towards a theoretical framework for research. In F. K. Lester Jr. (Ed.), Second handbook of research on mathematics teaching and learning (pp. 629-667). Reston, VA: National Council of Teachers of Mathematics

Landis, J., \& Koch, G. (1977). The measurement of observer agreement for categorical data. Biometrics, 33(1), 159-174. https://doi.org/10.2307/2529310

Lesh, R. (1979). Mathematical learning disabilities: Considerations for identification, diagnosis and remediation. In R. Lesh, D. Mierkiewicz, \& M. G. Kantowski (Eds.), Applied mathematical problem solving. Ohio: ERIC/SMEAC.

Leung, I. K., \& Carbone, R. E. (2013). Pre-service teachers' knowledge about fraction division reflected through problem posing. The Mathematics Educator, 14(1\&2), 80-92.

Li, Y. (2008). What do students need to learn about division of fractions? Mathematics Teaching in the Middle School, 13(9), 546-552.

Li, Y., \& Huang, R. (2008). Chinese elementary mathematics teachers' knowledge in mathematics and pedagogy for teaching: The case of fraction division. ZDM, 40(5), 845-859. https://doi.org/10.1007/s11858-008-0134-8

Li, Y., \& Kulm, G. (2008). Knowledge and confidence of pre-service mathematics teachers: the case of fraction division. ZDM-The International Journal of Mathematics Education, 40(5), 833-843. https://doi.org/10.1007/s11858-008-0148-2 
Lo, J., \& Luo, F. (2012). Prospective elementary teachers' knowledge of fraction division. Journal of Mathematics Teacher Education, 15(6), 481-500. https://doi.org/10.1007/s10857-012-9221-4

Ma, L. (1999). Knowing and teaching elementary mathematics. Mahwah, NJ: Lawrence Erlbaum Associates.

Mack, N. (1995). Confounding whole-number and fraction concepts when building on informal knowledge. Journal for Research in Mathematics Education, 26, 422-441. https://oi.org/10.2307/749431

National Council of Teachers of Mathematics (2014). Principles to action. Reston, VA: Author.

National Mathematics Advisory Panel. (2008). The foundations for success. Retrieved from http://www.ed.gov/about/bdscomm/list/mathpanel/report/final-report.pdf.

National Research Council (2009). Mathematics learning in early childhood: Paths toward excellence and equity. Washington D.C.: National Academies Press.

Nillas, L. (2003). Division of fractions: Preservice teachers' understanding and use of problem solving strategies. The Mathematics Educator, 7(2), 96-113.

Patton, M. (2002). Qualitative research \& evaluation methods (3 $3^{\text {rd }}$ ed.). Thousand Oaks, CA: Sage Publications.

Payne, J. (1976). Review of research on fractions. In R. Lesh (Ed.), Number and measurement (pp. 145-188). Athens, GA: University of Georgia.

Pett, M. (1997). Nonparametric statistics for health care research: Statistics for small samples and unusual distributions. Thousand Oaks, CA: Sage.

Philipp, R. \& Hawthorne, C. (2015). Unpacking referent units in fraction operations. Teaching Children Mathematics, 22(4), 240-247. https://doi.org/10.5951/teacchilmath.22.4.0240

Shin, J. (2010). Construction of a student-generated algorithm for fraction measurement division. Journal of Korea Society of Educational Studies in Mathematics, 12(3), 439-454.

Shulman, L. S. (1986). Those who understand: Knowledge growth in teaching. Educational Researcher, 15(2), 4-14. https://doi.org/10.3102/0013189X015002004

Siegler, R., Duncan, G., Davis-Kean, P., Duckworth, K., Claessens, A., Engel, M., et al. (2012). Early predictors of high school mathematics achievement. Psychological Science, 23, 691-697. https://oi.org/10.1177/0956797612440101

Tirosh, D. (2000). Enhancing prospective teachers' knowledge of children's conceptions: The case of division of fractions. Journal for Research in Mathematics Education, 31(1), 5-25. https://doi.org/10.2307/749817

Van de Walle, J. A. (2007). Elementary and middle school mathematics: Teaching developmentally (6 th $^{\text {ed.). }}$. Boston, MA: Pearson/Allyn and Bacon. 